\title{
Hubungan gagal jantung dan gangguan fungsi hati
}

\author{
${ }^{1}$ Adhytia B. C. P. Masola \\ ${ }^{2}$ Agnes L. Panda \\ ${ }^{2}$ Ventje Kawengian
}

\author{
${ }^{1}$ Kandidat Skripsi Fakultas Kedokteran Universitas Sam Ratulangi Manado \\ ${ }^{2}$ Bagian Ilmu Penyakit Dalam Fakultas Kedokteran Universitas Sam Ratulangi Manado \\ Email: aesadyth@gmail.com
}

\begin{abstract}
Heart failure is characterized by perfusion malfunction to fulfill the metabolism of the body caused by malfunction of heart pumps. It is oftenly associated with non-cardiac symptoms, such as liver dysfunction marked by increasing of liver function tests inter alia AST and ALT. This was a descriptive retrospective study using total sampling method. Subjects were medical records of heart failure patients who were hospitalized in Internal Medicine Department of Prof. Dr. R. D. Kandou Hospital Manado in 2013. Data included name, age, NYHA classification, as well as AST and ALT levels of heart failure patients. There were 36 subjects consisted of 23 males and 13 females. Based on NYHA classification, there were 24 patients with third class of NYHA and 12 patients with fourth class of NYHA. Most patients had increased AST and ALT levels over $100 \mathrm{U} / \mathrm{L}$. The chisquare test analyzing the relationship between NYHA and AST-ALT showed a p-value of 0.058. Conclusion: There was a relationship between heart failure and liver dysfunction, however, it was not statistically significant.
\end{abstract}

Keywords: heart failure, liver dysfunction, NYHA Class, AST, ALT

\begin{abstract}
Abstrak: Gagal jantung ditandai oleh ketidakmampuan perfusi sistemik memenuhi metabolisme tubuh yang disebabkan disfungsi pompa jantung. Gagal jantung dapat disertai gejala gangguan nonkardiak seperti gangguan fungsi hati ditandai dengan naiknya tes fungsi hati seperti AST dan ALT. Penelitian ini bertujuan untuk mengetahui hubungan gagal jantung dan gangguan fungsi hati. Jenis penelitian ialah deskriptif retrospektif dengan metode total sampling. Subjek penelitian ialah pasien gagal jantng di Bagian Ilmu Penyakit Dalam RSUP Prof. Dr. R. D. Kandou, Manado tahun 2013 yang diperoleh dengan metode total sampling. Data penderita gagal jantung berupa nama, jenis kelamin, usia, kelas NYHA, kadar AST, dan ALT diperoleh dari rekam medik. Jumlah subyek sebanyak 36 orang, terdiri dari 23 laki-laki dan 13 perempuan. Hasil penelitian memperlihatkan jumlah pasien gagal jantung kelas III NYHA 24 orang dan kelas IV NYHA 12 orang. Kebanyakan penderita mengalami peningkatan AST dan ALT diatas $100 \mathrm{U} / \mathrm{L}$. Analisis uji chi square terhadap kelas gagal jantung NYHA dengan AST dan ALT mendapatkan OR 3,6 dengan nilai $\mathrm{p}=0,058$ $(\mathrm{p}<0,05)$. Simpulan: Terdapat hubungan antara gagal jantung dan gangguan fungsi hati walau secara statistik tidak bermakna.
\end{abstract}

Kata kunci: gagal jantung, gangguan fungsi hati, kelas NYHA, AST, ALT

Jantung bekerja memompa darah yang kaya oksigen ke seluruh bagian tubuh. Jantung manusia berdetak rata-rata 100.000 kali per hari. Selama waktu itu, jantung memompa lebih dari 4.300 galon darah ke seluruh tubuh. ${ }^{1}$

Gagal jantung (heart failure) merupakan satu-satunya penyakit kardiovaskular yang terus meningkat 5-10\% insidennya per tahun. ${ }^{2}$ Di Amerika, 
National Heart, Lungs, and Blood Institute (NHLBI) melaporkan bahwa dari 1000 orang sampel, setelah berumur 65 tahun, terdapat 10 orang menderita gagal jantung. Pada usia 40 tahun, perbandingan laki-laki dan perempuan untuk risiko gagal jantung ialah 1:5. Untuk penderita gagal jantung baru berusia lebih dari 80 tahun, diduga hanya bisa bertahan hidup $20 \%$ untuk lakilaki dan perempuan. ${ }^{3}$

Pada tahun 2006, kematian yang disebabkan oleh gagal jantung di Amerika ialah 282.754 orang dengan jumlah lakilaki 159.167 orang dan perempuan 123.587 orang. Pada tahun 2007, gagal jantung menjadi penyebab utama pada 57.235 kematian. Menurut NHLBI, dari 8 kematian yang teridentifikasi 1 diantaranya disebabkan gagal jantung. ${ }^{3}$

Di Indonesia, berdasarkan data Riset Kesehatan Dasar Kementerian Kesehatan Indonesia tahun 2013 mengenai prevalensi gagal jantung dinyatakan bahwa penderita gagal jantung yang pernah didiagnosis dokter di Indonesia sebanyak $0,13 \%$ dan yang didiagnosis dan disertai gejala $0,3 \%$ dari 722.329 sampel berusia diatas 15 tahun. Untuk prevalensi di Provinsi Sulawesi Utara, penderita gagal jantung yang pernah didiagnosis $0,14 \%$, sedangkan penderita didiagnosis gagal jantung yang disertai gejala $0.4 \%{ }^{4}$

Gagal jantung ditandai oleh ketidakmampuan perfusi sistemik untuk memenuhi kebutuhan metabolisme tubuh dan biasanya disebabkan oleh disfungsi pompa jantung; kadang-kadang bisa disertai gejala gangguan non- kardiak seperti gangguan fungsi hati. Hal ini ditandai dengan meningkatnya kadar AST dan ALT yang menjadi patokan untuk abnormalitas fungsi hati. Patofisiologi utama yang terlibat dalam gangguan fungsi hati ialah salah satunya kongestif pasif dari peningkatan tekanan pengisisan atau curah jantung rendah dan akibat dari gangguan perfusi. $^{5}$

Gangguan fungsi hati terjadi karena meningkatnya tekanan vena sentralis sehingga mengakibatkan peningkatan enzim hati. $^{5}$
Penelitian ini bertujuan untuk mendapatkan hubungan gangguan fungsi hati dan gagal jantung di RSUP Prof. Dr. R. D. Kandou Manado sebagai Rumah Sakit Umum dan rujukan di Sulawesi Utara.

\section{METODE PENELITIAN}

Jenis penelitian ini ialah deskriptif retrospektif. Penelitian ini dilakukan pada bulan November sampai Desember 2014 menggunakan data rekam medik di RSUP Prof. Dr. R. D. Kandou Manado. Populasi dan sampel dari penelitian ialah seluruh pasien gagal jantung yang dirawat di RSUP Prof. Dr. R. D. Kandou Manado periode Januari tahun 2013 s/d Desember 2013.

Kriteria inklusi penelitian ini ialah pasien gagal jantung kelas III dan IV dan memiliki hasil pemeriksaaan darah sednagkan kriteria eksklusi ialah pasien dengan riwayat penyakit hati seperti hepatitis dan sirosis hati serta pasien yang didiagnosis gagal jantung kiri.

Data yang diperoleh dari rekam medik pasien diolah dan disajikan dalam tabel klasifikasi kelas NYHA. Untuk AST dan ALT rendah-menengah dengan kadar 0-100 U/L dan tinggi bila lebih dari $100 \mathrm{U} / \mathrm{L}^{6}{ }^{6}$

\section{HASIL PENELITIAN}

Subjek penelitian terdiri dari 36 data rekam medik pasien yang didiagnosis gagal jantung dari bulan Januari s/d Desember 2013. Gambar 1 memperlihatkan bahwa usia 50-69 tahun yang didiagnosis gagal jantung merupakan yang terbanyak dengan jumlah 21 pasien $(58,33 \%)$.

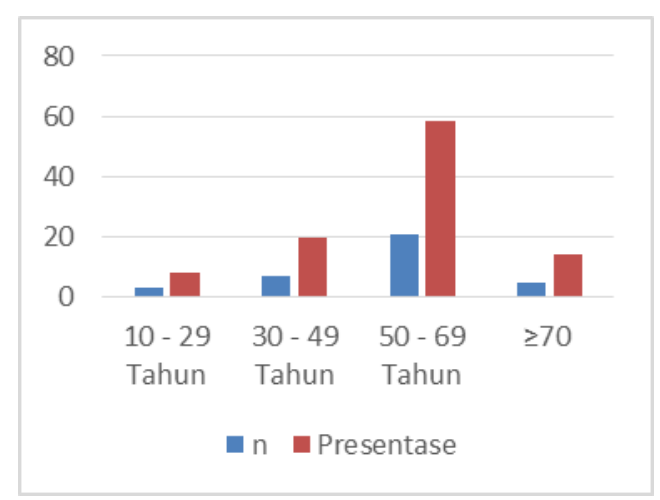

Gambar 1. Distribusi pasien gagal jantung berdasarkan usia 
Gambar 2 memperlihatkan bahwa pasien laki-laki yang didiagnosis gagal jantung dengan jumlah 23 sampel $(63,89 \%)$ lebih banyak daripada perempuan.

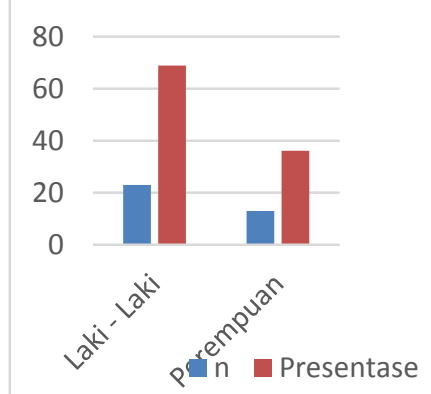

Gambar 2. Distribusi pasien gagal jantung berdasarkan jenis kelamin

Gambar 3 memperlihatkan bahwa klasifikasi NYHA kelas III paling banyak ditemukan pada pasien yang didiagnosis gagal jantung dengan jumlah 24 sampel $(61 \%)$.

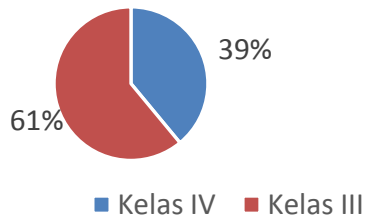

Gambar 3. Distribusi pasien gagal jantung berdasarkan klasifikasi NYHA

Tabel 1 memperlihatkan hasil kadar AST pada pasien gagal jantung kelas III NYHA untuk kategori kadar AST meningkat ringan-menengah berjumlah 5 orang $(13,89 \%)$ sedangkan pada ketegori yang sama untuk Kelas IV NYHA tidak ada sama sekali. Untuk ketegori kadar AST meningkat tinggi, pada kelas III NYHA berjumlah 19 orang $(52,78 \%)$ sedangkan kategori yang sama pada kelas IV NYHA berjumlah 12 pasien $(33,33 \%)$.

Tabel 2 memperlihatkan kadar ALT pada pasien gagal jantung kelas III NYHA untuk kategori kadar AST meningkat ringan-menengah berjumlah 6 orang $(16,67 \%)$ sedangkan untuk kategori yang sama pada Kelas IV NYHA tidak ada sama sekali. Untuk ketegori kadar AST meningkat tinggi, pada kelas III NYHA berjumlah 18 orang (50\%) sedangkan kategori yang sama pada kelas IV NYHA berjumlah 12 pasien $(33,33 \%)$.

Tabel 1. Distribusi pasien gagal jantung berdasarkan kadar AST

\begin{tabular}{clccc}
\hline & \multicolumn{3}{c}{ AST meningkat } \\
\cline { 2 - 5 } Kelas & \multicolumn{2}{c}{ Ringan -} & \multicolumn{2}{c}{ Tinggi } \\
NYHA & \multicolumn{2}{c}{ Menengah } & \multicolumn{2}{c}{$>100$ U/L } \\
& $0-100$ U/L & & \\
\cline { 2 - 5 } & $\mathrm{n}$ & $\%$ & $\mathrm{n}$ & $\%$ \\
\hline III & 6 & 16,67 & 18 & 50 \\
IV & - & 0 & 12 & 33,33 \\
Total & 6 & 16,67 & 30 & 83,33 \\
\hline
\end{tabular}

Tabel 2. Distribusi pasien gagal jantung berdasarkan ALT

\begin{tabular}{ccccc}
\hline & \multicolumn{3}{c}{ ALT Meningkat } \\
\cline { 2 - 5 } Kelas & \multicolumn{2}{c}{ Ringan -} & \multicolumn{2}{c}{ Tinggi } \\
NYHA & \multicolumn{2}{c}{$\begin{array}{l}\text { Menengah } \\
0-100\end{array} / \mathrm{L}$} & \multicolumn{2}{c}{$>100$ U/L } \\
\cline { 2 - 5 } & $\mathrm{n}$ & $\%$ & $\mathrm{n}$ & $\%$ \\
\hline III & 6 & 16,67 & 18 & 50 \\
IV & - & 0 & 12 & 33,33 \\
Total & 6 & 16,67 & 30 & 83,33 \\
\hline
\end{tabular}

Hasil pengujian Pearson Chi-Square, mengenai hubungan antara kelas NYHA dan hasil AST mendapatkan nilai signifikansi 0,058 $(\mathrm{p}<0,05)($ Tabel 3).

Tabel 3. Uji chi-square pasien gagal jantung dan AST

\begin{tabular}{|c|c|c|c|c|}
\hline \multirow{2}{*}{$\begin{array}{c}\text { Kelas } \\
\text { NYHA }\end{array}$} & \multicolumn{2}{|c|}{ AST meningkat } & \multirow[b]{2}{*}{ Ratio } & \multirow[b]{2}{*}{$\mathbf{P}$} \\
\hline & $\begin{array}{c}\text { Ringan - } \\
\text { Menengah }\end{array}$ & Tinggi & & \\
\hline III & 6 & 18 & \multirow{2}{*}{3,6} & \multirow{2}{*}{0,058} \\
\hline IV & 0 & 12 & & \\
\hline Total & 6 & 30 & 3,6 & 0,058 \\
\hline
\end{tabular}

Hasil pengujian Pearson Chi-Square mengenai hubungan antara kelas NYHA dan hasil AST mendapatkan nilai signifikansi 0,058 $(\mathrm{p}<0,05)($ Tabel 4). 
Tabel 4. Uji chi-square pasien gagal jantung dan ALT

\begin{tabular}{ccccc}
\hline $\begin{array}{r}\text { Kelas } \\
\text { NYHA }\end{array}$ & \multicolumn{2}{c}{ ALT meningkat } & & Odd \\
\cline { 1 - 3 } & $\begin{array}{c}\text { Ringan - } \\
\text { Menengah }\end{array}$ & Tinggi & Ratio & \\
\hline III & 6 & 18 & 3,6 & 0,058 \\
IV & 0 & 12 & & \\
Total & 6 & 30 & 3,6 & 0,058 \\
\hline
\end{tabular}

\section{BAHASAN}

Penelitian ini menggunakan data rekam medik 36 oang pasien gagal jantung periode Januari s/d Desember 2013. Data usia subjek penelitian berkisar antara 19-84 tahun dengan jumlah terbanyak pada usia 50-69 tahun. Jumlah data laki-laki 23 pasien, sedangkan perempuan berjumlah 13 pasien. Menurut klasifikasi NYHA, penderita kelas III merupakan jumlah terbanyak dengan 24 sampel (61\%).

Berdasarkan hasil penelitian, pasien gagal jantung kelas III NYHA memiliki hasil AST dan ALT yang sama. Kategori "meningkat tinggi" paling banyak ditemukan dengan jumlah 18 dari 24 sampel. Untuk kelas IV NYHA, kategori "meningkat berat" yang paling banyak ditemukan dengan jumlah 12 sampel dari total sampel. Analisis hubungan antara gagal jantung dan gangguan fungsi hati menggunakan uji chi square. Sebagai pembanding, penelitian Alvarez et al. ${ }^{5}$ di Amerika yang menggunakan jumlah 110 sampel terdiri dari 72 laki-laki dan 38 perempuan. Hasil penelitian tersebut menunjukkan adanya hubungan antara gagal jantung dan gangguan fungsi hati dengan adanya peningkatan AST dan ALT pada uji fungsi hati untuk pasien gagal jantung meningkat 2-3 kali dari kadar normal namun tidak bermakna.

Peningkatan AST dan ALT disebabkan regurgitasi triskupid (TR) yang sangat rentan menghasilkan gangguan pasif karena tekanan dari ventrikel kanan ditransmisikan langsung ke pembuluh darah hati dan sinusoid. Peningkatan tekanan vena mengakibatkan gagal ventrikel kanan dan menyebabkan atrofi. ${ }^{5}$

Pada penelitian ini hasil uji chi square menunjukkan adanya hubungan tidak bermakna antara gagal jantung dengan hasil AST dan ALT ( $\mathrm{p}=0,058)$. Hasil ini tidak sejalan dengan penelitian dari Avarez et al. ${ }^{5}$ yang menggunakan sampel dan variabel yang lebih banyak dengan hasil uji chisquare nilai signifikansi ALT ialah $\mathrm{p}=0,00018$ dan nilai signifikansi AST ialah $\mathrm{p}=0,0009$ (nilai kebenaran $\mathrm{p}<0,001$ ). Perbedaan hasil kedua penelitian ini mungkin disebabkan karena jumlah sampel (110 sampel) dan variabel (6 variabel) yang digunakan oleh Alvarez et al. ${ }^{5}$ lebih besar sehingga hasil penelitian ini tidak menunjukkan hubungan bermakna antara gagal jantung dan gangguan fungsi hati.

Keterbatasan dari penelitian ini dikarenakan jumlah sampel yang sesuai kriteria inklusi dan eksklusi yang sedikit serta jumlah variabel yang digunakan sedikit. Juga jumlah penelitian yang serupa yang sangat sedikit sebagai pembanding dengan penelitian ini.

\section{SIMPULAN}

Dari hasil penelitian pada pasien gagal jantung di RSUP Prof. Dr. R. D. Kandou Manado dapat disimpulkan bahwa terdapat hubungan tidak bermakna antara gagal jantung kiri dan ganguan fungsi hati.

\section{SARAN}

Perlu dilakukan penelitian lanjut dengan menggunakan sampel dan variabel yang lebih banyak agar hasil penelitian ini semakin akurat.

\section{DAFTAR PUSTAKA}

1. Elizabeth E. Heart structure, function, arrhythmias. Department of Medical Science: New York [online]. 2010. [cited 2014 Oct 4]. Available from: URL:http//thevirtualheart.org/3dpdf/h eart_3d.pdf.h.1

2. Kasron. Buku ajar gangguan sistem kardiovaskular. Yogyakarta: Nusa Medika, 2012; p. 55.

3. Donald LJ, Robert JA, Todd MB, Mercedes C, Shifan D, Giovanni DS, et al. Heart failure and stroke statistic. American Heart Association [online]. 2010, [cited 2014 Oct 3]. 
Available from: URL:http: //circ.ahajournals.org/content/121/7/e 46.full.pdf.h.e56-58

4. Riset kesehatan dasar 2013. Jakarta: Kementrian RI [online]. 2013. [cited 2014 Oct 3]. Available from:URL: http://www.litbang.depkes.go.id/sites/ download/rkd2013/Laporan_Riskesda s2013.pdf.p.83

5. Alvarez MA, Mukherjee D. Liver abnormalities in cardiac disease and heart failure. Int $\mathrm{J}$ Angiol. 2011;20(3):135-40.

6. Allen LA, Felker GM, Pocock S. Liver function abnormalities and outcome in patients with chronic heart failure. Candesartan in heart failure: assessment of reduction in mortality and morbidity (CHARM) program. Eur J Heart Fail. 2009;11(2):170-7.

7. Longo DL, Fauci AS. Harrison Gastroenterologi \& hepatologi. Jakarta: EGC, 2010; p. 299-303.

8. Myres RP, Cerini R, Sayegh R. Cardiac hepatopathy: clinical, hemodynamic, and histologic characteristic correlation. Hepatology [online]. 1992. [cited 2014 Oct 22]. Available from: http://www.ncbi.nlm.nih.gov/ pubmed/12540790.p.393-400. 